\title{
Effects of Monoglyceride Fatty Acid Species on the Properties of Dough Protein
}

\author{
Shigetaka Inoue, ${ }^{1}$ Kazumasa Tugita, ${ }^{1}$ Seiji KoIKe, ${ }^{2}$ Kazuaki SuZUKI $^{2}$ and Ikuzo KAMOI ${ }^{3}$ \\ ${ }^{1}$ Central Laboratory, Yamazaki Baking Co., Ltd., 3-15-6, Chitose, Sumida-ku, Tokyo 130, Japan \\ ${ }^{2}$ Basic Research Laboratory, Asahi Denka Kogyo K.K., 8-4-1, Higashiogu, Arakawa-ku, Tokyo 116, Japan \\ ${ }^{3}$ Department of Agricultural Chemistry, Tokyo University of Agriculture, 1-1-1, Sakuragaoka, Setagaya-ku, Tokyo 156, Japan
}

Received August 25, 1995

\begin{abstract}
We investigated the influence of three types of monoglycerides, glyceryl monostearate (monostearate), glyceryl monooleate (monooleate) and glyceryl monoelaidate (monoelaidate), on protein during dough preparation. The addition of monooleate and monoelaidate decreased the amount of protein in the ethanol soluble fraction (corresponding to gliadin) and increased the water soluble fraction. Monostearate did not produce these changes in the protein fractions. The quantities of monooleate and monoelaidate in the ethanol soluble fractions were larger than that of the monostearate. The surface hydrophobicity of the water soluble protein and the $0.01 \mathrm{~N}$ acetic acid soluble protein in the dough was determined using the magnesium of 1-anilino-8-naphthalenesulfonic acid. The doughs containing monooleate or monoelaidate showed a decrease in the hydrophobicity of the proteins. After the defatting operation with butanol to remove the monoglycerides, the surface hydrophobicity of these defatted proteins nearly increased to the level of protein which contained no added monoglyceride. It was indicated that the unsaturated monoglycerides, monooleate and monoelaidate were adsorbed into the protein during the dough mixing and lowered the surface hydrophobicity. It was considered that the presence of a double-bond component in the fatty acid may cause bonding to the dough protein.
\end{abstract}

Keywords: hydrophobic interaction, protein surface hydrophobicity, gliadin, monoglyceride

Monoglycerides have been used as an important modifier in bread making for many years, to improve bread volume, dough strength and bread crumb softness, and to reduce bread staling. Numerous studies have determined the role of monoglycerides in bread making in terms of its emulsification or agglomeration of fat globules, formation of complex starches, and its interaction with protein in the presence of water. Morad \& D'Appolonia (1980) reported that the amount of soluble starch in bread crumbs decreased in the presence of a monoglyceride. Joensson \& Toernaes (1987) reported that bread crumb firmness decreased in the presence of a monoglyceride. In Krog et al. (1989) and Yamauchi et al. (1992) articles, they suggested the existence of an amylosemonoglyceride complex using differential scanning calorimetry (DSC) and X-ray diffraction. There have been many studies made to reduce bread staling with monoglyceride addition. We investigated the effect of a species of fatty acid consisting of monoglycerides on dough properties (Inoue et al., 1995). Monooleate and monoelaidate definitely decreased dough consistency during mixing and increased the physical strength of the dough during extension whereas these effects were not observed with the monostearate addition. It was suggested that the changes in dough characteristics with the addition of monoglycerides were caused by the binding of monoglycerides to the protein through hydrophobic interaction thus resulting in a change in the protein conformation. Studies of monoglyceride-protein interaction were reported in such papers as Mendoza-Martinez \& Sherman (1990a, 1990b, 1991) (The Influence of Water Soluble Meat Proteins in Corn Oil in Water Emulsions), and Haehnel et al. (1994) (The Influence of Amino Acids in Gluten Systems). The studies of lipid-protein interaction have also been reported such as the interaction between phospholipids and ovalbumin analyzed by nuclear magnetic resonance (Mine et al., 1993) and the interaction between triglycerides and various native or chemically modified proteins (Smith et al, 1983). Yuno-Ohta et al. $(1988,1992)$ reported the effect of sodium caprylate, sodium oleate and sodium linoleate on the gel preparation of sesame 13S globulin. Kobrehel \& Bushuk (1977) reported the effect of various fatty acid salts on the solubility of gluten. In this study, we investigated the effects of three types of monoglycerides, monostearate as a saturated monoglyceride model, monooleate as a cis-unsaturated monoglyceride model and monoelaidate as a trans-unsaturated monoglyceride model, on dough proteins and also discussed the mechanism of changes in dough properties by addition of these monoglycerides.

\section{Materials and Methods}

Materials The monoglycerides used in this study were described in a previous report (Inoue et al., 1995). The fatty acids, stearic acid (>97\%, Nippon Oils \& Fats Co., Ltd., Tokyo), oleic acid (>99\%, Tokyo Kasei Kogyo Co., Ltd., Tokyo) and elaidic acid (>99\%, Wako Pure Chemical Ind., Ltd., Osaka) were reacted with glycerol under a vacuum at $200^{\circ} \mathrm{C}$ for $2-3 \mathrm{~h}$. The resulting monoglycerides were purified by molecular distillation and florisil column chromatography. The purities of the monoglycerides were $>99 \%$ as deter- 
mined by thin layer chromatography with a flame ionization detector (TLC/FID Analyser, IATROSCAN MK-5, Iatron Co., Ltd., Tokyo). Sodium thiocyanate (NaSCN) was purchased from Wako Pure Chemical Ind., Ltd., Osaka. The flour used was a commercial unbleached wheat flour which was supplied by Nisshin Flour Milling Co., Ltd., Tokyo. It contained $11.8 \%$ protein $(\mathrm{N} \times 5.7)$ and $0.37 \%$ ash.

Preparation of dough and gluten The monoglyceride was added to the flour after dispersion in a little water by ultrasonication. The monoglycerides, in amounts ranging from 0.2 to $1.0 \%$ (w/w, flour basis), were mixed with wheat flour in a $300 \mathrm{~g}$ Farinograph mixing bowl. After mixing thoroughly, distilled water was added (65\% of the flour basis) and then the dough was mixed for an optimum development time until the dough reached $30^{\circ} \mathrm{C}$. In the experiments concerning the effects of $\mathrm{NaSCN}$ on the dough consistency, the NaSCN was directly added to the flour ranging from 0.017 to $0.33 \mathrm{mmol} / 10 \mathrm{~g}$ flour. The dough preparation was the same as those using the monoglyceride. The gluten was separated from the resulting dough by continuously kneading with distilled water using a Glutomatic 2202 System (Falling Number Co., Ltd., Sweden).

Extraction of free and total monoglyceride from gluten The gluten was freeze-dried and ground to a fine powder. A portion of the gluten powder was vigorously stirred with diethyl ether for $2 \mathrm{~h}$ and the "free lipids" were extracted. Another portion of the gluten powder was digested with pepsin in a dilute sulfuric acid $(\mathrm{pH} 1.5-2.0)$ at $40^{\circ} \mathrm{C}$ overnight and the "total lipids" in gluten were obtained by extracting with water-saturated butanol. The solvent in each extract was evaporated to dryness, and the residual solutes were weighed to obtain the amount of "free" and "total" lipids.

The compositions of the extract were determined by thin layer chromatography using a flame ionization detector (TLC/FID) method. The extract was dissolved in $1 \mathrm{ml}$ of chloroform/methanol $(2: 1, \mathrm{v} / \mathrm{v})$ and $1 \mu 1$ of the solution was applied on a glass capillary rod coated with silica gel and subjected to double developing chromatography to obtain the monoglyceride, triglyceride and polar lipids. The glass capillary rod was developed to a distance of $5 \mathrm{~cm}$ from the origin with solvent (A) of chloroform/methanol/water (65: $25: 4$ by vols) then developed again to a distance of $10 \mathrm{~cm}$ with solvent (B) of benzene/chloroform/acetic acid/methanol $(50: 20: 0.7: 0.5$ by vols). The monoglyceride content in the extract was calculated from the amount of the extract and the ratio of monoglyceride in the extract. The adsorbed monoglyceride content in gluten was obtained by subtracting the "free" monoglyceride content from the "total" monoglyceride content.

Fractionation of dough protein The water soluble protein of the dough $(15 \mathrm{~g})$ was extracted using $150 \mathrm{ml}$ distilled water with gentle stirring at room temperature. The starch in the extracts was removed by centrifugation. After extracting the water soluble proteins, the gluten was separated from the dough using a Glutomatic 2202 System. The gluten was dispersed in $200 \mathrm{ml} 0.1 \mathrm{~N}$ acetic acid and the dispersion was vigorously stirred for $30 \mathrm{~min}$ at room temperature. This suspension was centrifuged at $30,000 \times g$ for $30 \mathrm{~min}$ and the precipitate was designated as the "acetic acid insoluble fraction." The $0.1 \mathrm{~N}$ acetic acid soluble protein was fractionated into three fractions according to the method of Danno et al. (1978) and Shiiba et al. (1993). The $0.1 \mathrm{~N}$ acetic acid soluble protein in the supernatant was suspended in $0.5 \%$ sodium dodecyl sulfate (SDS) solution containing 1\% 2mercaptoethanol at $25^{\circ} \mathrm{C}$ for $4 \mathrm{~h}$ to reduce the interpolypeptide disulfide bond. The reduced polypeptide was alkylated by treatment with a 2:1 molar ratio of acrylonitrile to 2-mercaptoethanol at a $\mathrm{pH}$ of 7.4 for $40 \mathrm{~min}$. The reaction solution, which contained $1 \%$ protein, was diluted with 2.4 times the volume of ethanol. The suspension was adjusted to a pH of 5.2 with $1 \mathrm{~N} \mathrm{NaOH}$. After standing at $25^{\circ} \mathrm{C}$ for $30 \mathrm{~min}$, the suspension was centrifuged at $30,000 \times g$ for $30 \mathrm{~min}$ and the obtained precipitate was the "ethanol insoluble fraction I." The supernatant was then adjusted to $\mathrm{pH}$ of 6.7 with $1 \mathrm{~N}$ $\mathrm{NaOH}$. After standing at $5^{\circ} \mathrm{C}$ overnight, the suspension was centrifuged and the obtained precipitate was designated as "ethanol insoluble fraction II." The ethanol in the supernatant was evaporated and the residue was defined as the "ethanol soluble fraction." The nitrogen content in these fractions was determined by the micro-Kjeldahl method or a nitrogen analyzer (CHN CORDER MT-3, Yanako Co., Ltd.) and the "protein content" was calculated using 5.7 as the conversion factor. The monoglycerides in each fraction were extracted with chloroform/methanol $(2: 1, \mathrm{v} / \mathrm{v})$ and a quantitative analysis was carried out using the TLC/FID method.

The measurement of protein surface hydrophobicity The protein surface hydrophobicity was determined using a hydrophobic fluorescence probe of a magnesium salt of 1-anilino-8-naphthalenesulfonic acid (ANS) according to the method published by Hayakawa \& Nakai (1985). The protein sample was diluted with a $0.01 \mathrm{M}$ phosphate buffer to adjust the protein concentration to $0.02 \%$. Ten $\mu 1$ of $8 \mathrm{mM}$ ANS in a $0.1 \mathrm{M}$ phosphate buffer solution $(\mathrm{pH} 7)$ was added to $2 \mathrm{ml}$ of protein solution. This mixture was allowed to stand at $20^{\circ}$ $\mathrm{C}$ for $2 \mathrm{~h}$. The fluorescence intensity was measured with a Shimazu RE-5000 spectrophotofluorometer at excitation and emission wavelengths of 380 and $480 \mathrm{~nm}$, respectively. The protein concentration was determined by Pierce BCA method using bicinchoninic acid reagent and bovine serum albumin (BSA) as a standard. Hydrophobicity was expressed as fluorescence intensity divided by protein concentration.

\section{Results and Discussion}

The amount of monoglycerides adsorbed to gluten by dough mixing As shown in Fig. 1, the amount of adsorbed monooleate and monoelaidate increased in proportion to the added amount of monoglycerides. Monostearate was found to be hardly adsorbed to gluten, but slight adsorption was observed at high monoglyceride content levels. It was also shown that monooleate has a higher adsorption than monoelaidate at concentrations greater than $0.6 \%$ (based on flour weight).

In a previous report (Inoue et al., 1995), it was indicated that monooleate and monoelaidate existed in the gluten at an approximately 20 times higher level than monostearate where the monoglyceride content level during mixing was $0.6 \%$ (based on flour weight). Furthermore, Riisom et al. (1984) 
have reported that the cis-unsaturated monoglycerides were bound to the gluten and the starch fractions to a higher extent at the dough stage, whereas the monopalmitate remained free at the dough stage. In our experiments, it was found that the adsorptive properties of gluten differed among the three types of monoglycerides. It was suggested that the reason for this difference may lie in the difference in the structure of the fatty acids which constitute a monoglyceride. Unsaturated monoglycerides, such as monooleate, monoelaidate were easily bound to the gluten, whereas saturated monoglycerides, such as monostearate were hardly bound to the gluten.

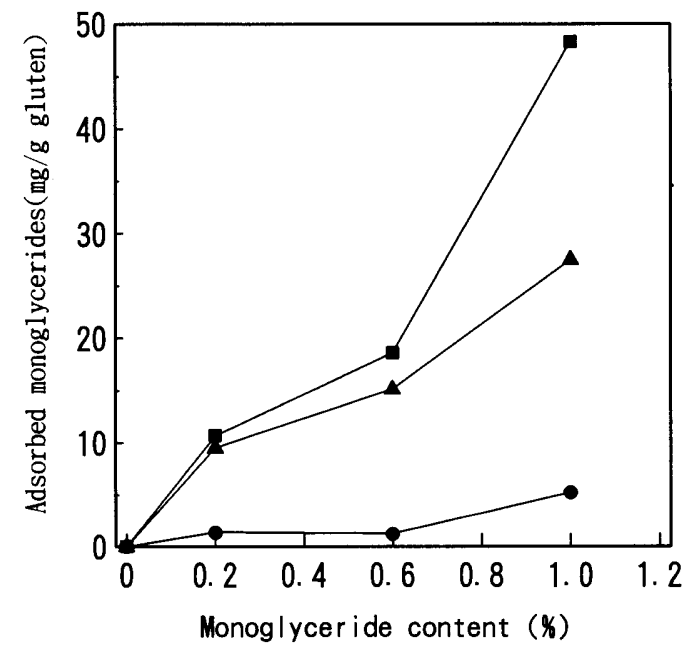

Fig. 1. The amount of monoglyceride adsorbed in gluten by dough mixing - monostearate, $\mathbf{a}$ monooleate, $\boldsymbol{\Delta}$ monoelaidate. Adsorbed monoglyceride $=$ Total monoglyceride-Free monoglyceride. Total monoglyceride extracted with water saturated butanol after digested with pepsin. Free monoglyceride extracted with ether.
Effect of various monoglycerides on the protein distribution in dough protein The effects of monostearate, monooleate and monoelaidate on the protein distribution of dough protein were investigated (Table 1). Table 1 shows the amount of proteins contained in each protein fraction. The ethanol insoluble fraction I and fraction II corresponds to polypeptides of glutenins precipitated at $\mathrm{pH} 5.2$ and $\mathrm{pH}$ 6.7, respectively. The ethanol soluble fraction corresponds to the polypeptides of the gliadins. The acetic acid insoluble fraction corresponds to the insoluble glutenins. The total recoveries of protein were greater than $95 \%$ throughout the experiments. The amounts of proteins in the ethanol soluble fraction were $456.4,418.4$ and $420.3 \mathrm{mg}$ for no added monoglyceride, monooleate, and monoelaidate, respectively. It was found that the addition of unsaturated monoglycerides, monooleate and monoelaidate tends to decrease the ethanol soluble fraction by as much as approximately $8 \%$ and to increase the water soluble fraction by $19 \%$ to 23 as compared with the dough containing no added monoglyceride. The ethanol insoluble fraction II slightly decreased with the addition of monooleate or monoelaidate. No remarkable change in the other protein fractions was observed. On the other hand, monostearate did not produce these significant changes in the protein fractions. Chung \& Tsen (1975) reported that the addition of ethoxylated monoglycerides decreased the amount of proteins in the gliadin fraction, and increased the nonprotein nitrogenous fraction using the gel filtration procedure. This finding agrees with our results.

It is suggested that monooleate and monoelaidate mainly operate on gliadin, and thereby changes the solubility of gliadin. A part of the gliadin is considered to be dissolved in the water fraction.

Monoglycerides associated with protein fractions Table 2 shows the monoglyceride content in each protein fraction.

Table 1. Effect of monoglycerides on proportion of fractionated protein.

\begin{tabular}{|c|c|c|c|c|c|c|c|}
\hline \multirow[b]{2}{*}{ Dough } & \multicolumn{5}{|c|}{ Fractionated protein $(\mathrm{mg})$} & \multirow{2}{*}{$\begin{array}{l}\text { Total protein } \\
(\mathrm{mg})\end{array}$} & \multirow{2}{*}{$\begin{array}{c}\text { Total recovery } \\
(\%)\end{array}$} \\
\hline & $\begin{array}{l}\text { Ethanol insoluble } \\
\text { fraction I }\end{array}$ & $\begin{array}{l}\text { Ethanol insoluble } \\
\text { fraction II }\end{array}$ & $\begin{array}{c}\text { Ethanol soluble } \\
\text { fraction }\end{array}$ & $\begin{array}{c}\text { Acetic acid } \\
\text { insoluble fraction }\end{array}$ & $\begin{array}{l}\text { Water soluble } \\
\text { fraction }\end{array}$ & & \\
\hline None & $\begin{array}{l}89.6 \\
(9.3)^{b)}\end{array}$ & $\begin{array}{l}116.8 \\
(12.2)\end{array}$ & $\begin{array}{l}456.4 \\
(47.6)\end{array}$ & $\begin{array}{c}96.8 \\
(10.1)\end{array}$ & $\begin{array}{l}200.0 \\
(20.8)\end{array}$ & 959.6 & 96.2 \\
\hline $\begin{array}{l}\text { Monostearate added } \\
\qquad\left(0.6 \%^{a)}\right)\end{array}$ & $\begin{array}{l}96.4 \\
(9.9)\end{array}$ & $\begin{array}{l}120.4 \\
(12.4)\end{array}$ & $\begin{array}{l}448.0 \\
(46.1)\end{array}$ & $\begin{array}{l}91.6 \\
(9.4)\end{array}$ & $\begin{array}{l}215.0 \\
(22.1)\end{array}$ & 971.4 & 98.1 \\
\hline $\begin{array}{l}\text { Monooleate added } \\
\quad(0.6 \%)\end{array}$ & $\begin{array}{l}94.8 \\
(9.9)\end{array}$ & $\begin{array}{c}98.0 \\
(10.3)\end{array}$ & $\begin{array}{l}418.4 \\
(43.8)\end{array}$ & $\begin{array}{l}99.5 \\
(10.4)\end{array}$ & $\begin{array}{l}245.0 \\
(25.6)\end{array}$ & 955.7 & 95.9 \\
\hline $\begin{array}{l}\text { Monoelaidate added } \\
\quad(0.6 \%)\end{array}$ & $\begin{array}{c}97.2 \\
(10.2)\end{array}$ & $\begin{array}{l}102.8 \\
(10.7)\end{array}$ & $\begin{array}{l}420.3 \\
(43.9)\end{array}$ & $\begin{array}{c}98.2 \\
(10.3)\end{array}$ & $\begin{array}{l}239.0 \\
(24.9)\end{array}$ & 957.5 & 95.7 \\
\hline
\end{tabular}

a) Monoglyceride/wheat flour (w/w). ${ }^{b)}$ Percent of total protein.

Table 2. Monoglyceride content in protein fractions.

\begin{tabular}{lccc}
\hline \multirow{2}{*}{ Dough } & & \multicolumn{2}{c}{ Monoglyceride $(\mu$ mol $)$} \\
\cline { 2 - 4 } & $\begin{array}{c}\text { Ethanol insoluble } \\
\text { fractions I and II }\end{array}$ & $\begin{array}{c}\text { Ethanol soluble } \\
\text { fraction }\end{array}$ & $\begin{array}{c}\text { Acetic acid insoluble } \\
\text { fraction }\end{array}$ \\
\hline Monostearate added $\left(0.6 \%^{a)}\right)$ & 2.8 & 2.0 & 0.8 \\
Monooleate added $(0.6 \%)$ & 4.1 & 21.0 & 2.7 \\
Monoelaidate added $(0.6 \%)$ & 2.4 & 17.0 & 0 \\
\hline
\end{tabular}

a) Monoglyceride/wheat flour (w/w). 
The amounts of monoglycerides in the ethanol soluble fraction from $15 \mathrm{~g}$ of dough were $2.0,21.0$ and $17.0 \mu \mathrm{mol}$ in for the monostearate, monooleate and monoelaidate, respectively. Similarly, the amounts of monoglycerides in the water soluble fraction were $0.2 \mu \mathrm{mol}$ for the monooleate and monoelaidate. The monostearate in the water soluble fraction could not be detected because of its very small content. The quantities of monooleate and monoelaidate in the ethanol soluble fractions were approximately 10 times and 8 times as much as the monostearate, respectively. The monoglyceride is so strongly fixed to protein that it is not easily extracted during the simple fractionation treatment with $70 \%$ ethanol. In the acetic acid insoluble fraction, monooleate and monoelaidate were detected in larger quantities than the monostearate. Comparing to unsaturated monoglycerides in the four protein fractions, the ethanol soluble fraction was found to contain the most monoglyceride. These results clearly indicate that the monooleate and monoelaidate are mainly adsorbed to gliadin.

Inakuma et al. (1989) reported that the role of gliadin on a dough's physical properties was the quantitative control of immobilized water in the dough. We suggest that the changes in the dough's reological properties are attributable to the changes in the properties of the gliadin by the monoglycerides.

Effect of various monoglycerides on hydrophobicity of water soluble proteins and $0.01 \mathrm{~N}$ acetic acid soluble proteins In the presence of monooleate or monoelaidate, the hydrophobicity of the water soluble proteins decreased at monoglycerides contents (based on flour weight) greater than $0.2 \%$ (Fig. 2a) and the hydrophobicity of $0.01 \mathrm{~N}$ acetic acid soluble proteins decreased with increasing content level (Fig. 2b). In the presence of monostearate, the hydrophobicity of both proteins also decreased, but the degree of decrease was much less than that of monooleate or monoelaidate. From these results, it is considered that monoglycerides are adsorbed to and mask the protein hydrophobic regions, and ANS binding was inhibited to the protein. In order to support this reasoning, the water soluble proteins and the $0.01 \mathrm{~N}$ acetic acid soluble proteins were defatted by butanol to remove the monoglycerides from these proteins, and the hydrophobicity was measured. As shown in Figs. $2 \mathrm{c}$ and $2 \mathrm{~d}$, the hydrophobicity of each defatted protein nearly increased to almost the level as the protein which contains no added monoglycer-
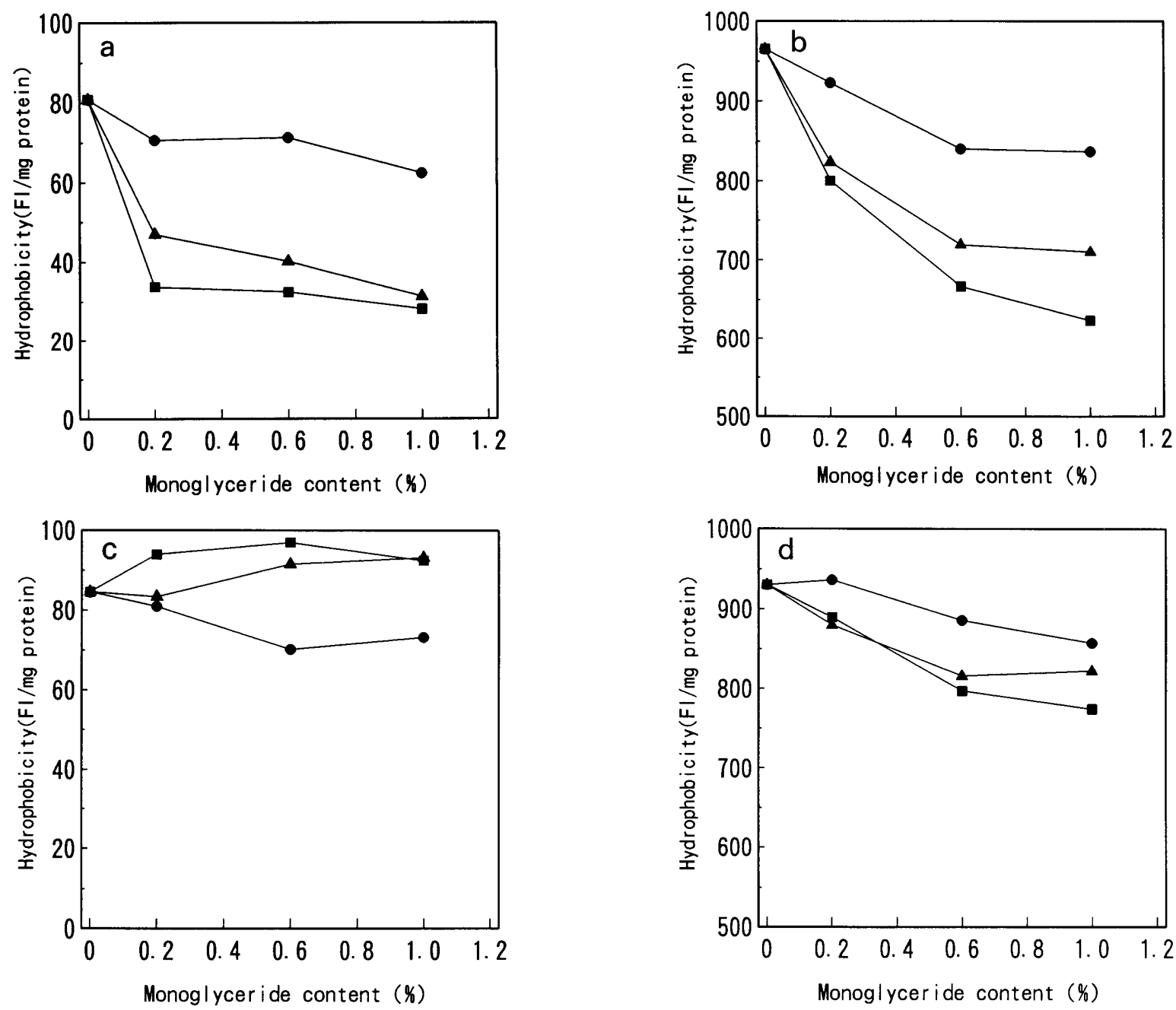

Fig. 2. Effect of monoglyceride concentration on surface hydrophobicity of water soluble protein and $0.01 \mathrm{~N}$ acetic acid soluble protein in dough. (a) water soluble protein, (b) $0.01 \mathrm{~N}$ acetic acid soluble protein, (c) water soluble protein defatted by butanol, (d) $0.01 \mathrm{~N}$ acetic acid soluble protein defatted by butanol. $\bullet$ monostearate added, $\mathbf{a}$ monooleate added, $\Delta$ monoelaidate added. 
ide. But, complete recovery of the hydrophobicity was not obtained upon the same treatment with respect to the $0.01 \mathrm{~N}$ acetic acid soluble proteins. Table 3 shows the hydrophobicity of each protein fraction. Monooleate and monoelaidate decreased the hydrophobicity of the ethanol soluble fraction by as much as $50 \%$ and $40 \%$, respectively, compared to those fractions without additives. These results indicate that the surface hydrophobicity of dough proteins is decreased with the addition of monoglycerides, and these effects were remarkable with the addition of monooleate and monoelaidate. It was also shown that monoglycerides contribute to a decrease in the hydrophobicity of gliadin. We suggested that the decrease in the surface hydrophobicity was one important factor for improving the dough's rheological properties.

Effect of hydrophobic bond decreasing reagent on dough consistency We consider that the change in dough protein hydrophobicity is one of the major factors contributing to the improvement in dough properties, such as the decrease in maximum consistency during mixing. In order to ascertain these guesses, we examined the effect of a hydrophobic bond decreasing reagent on dough consistency. NaSCN, which is generally known as a hydrophobic bond decreasing reagent, was used in this experiment. Figure 3

Table 3. Surface hydrophobicity of each protein fraction.

\begin{tabular}{lccc}
\hline \multirow{2}{*}{ Dough } & \multicolumn{3}{c}{ Surface hydrophobicity $\left(\mathrm{FI}^{a)} / \mathrm{mg}\right.$ protein $)$} \\
\cline { 2 - 4 } & $\begin{array}{c}\text { Ethanol } \\
\text { insoluble } \\
\text { fraction I }\end{array}$ & $\begin{array}{c}\text { Ethanol } \\
\text { insoluble } \\
\text { fraction II }\end{array}$ & $\begin{array}{c}\text { Ethanol } \\
\text { soluble } \\
\text { fraction }\end{array}$ \\
\hline None & 313.4 & 149.7 & 894.8 \\
Monostearate added $\left(0.6 \%^{b)}\right)$ & 262.5 & 127.4 & 934.2 \\
Monooleate added $(0.6 \%)$ & 254.4 & 198.1 & 455.3 \\
Monoelaidate added $(0.6 \%)$ & 263.5 & 142.2 & 546.5 \\
\hline
\end{tabular}

a) Fluorescence intensity at $\lambda$ ex. $380 \mathrm{~nm}$ and $\lambda$ em. $480 \mathrm{~nm}$

b) Monoglyceride/wheat flour $(w / w)$.

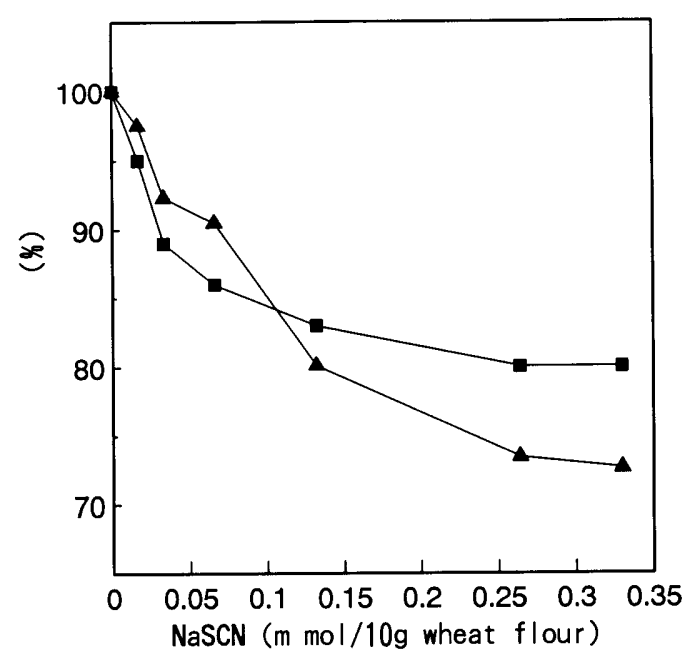

Fig. 3. Effect of NaSCN concentration on surface hydrophobicity and dough consistency. Values of surface hydrophobicity and dough consistency in the absence of $\mathrm{NaSCN}$ were converted into $100 \%$. $\Delta$ hydrophobicity, consistency. shows the effect of $\mathrm{NaSCN}$ concentration on hydrophobicity and dough consistency. In the presence of $\mathrm{NaSCN}$, both the hydrophobicity and the maximum consistency during mixing decreased with an increase in NaSCN concentration. Khan \& Bushuk (1978) proposed their model for the structure of glutenin. According to the model, it contains two types of glutenin subunits chemically bound to each other through disulfide bonds with some secondary bonds such as hydrophobic interactions and hydrogen bonds. Danno \& Hoseney (1982) reported that the addition of SDS or $\mathrm{NaCl}$ could reversibility recover the elastic state of the dough from its overmixing state. They guessed that these effects are attributed to the hydrophobic exterior or interior configuration of the glutenin structure. The rheological properties of the dough would essentially depend on these chemical behaviors in the glutenin structure.

We suggest that the change in the properties of dough with the addition of monoglyceride, such as the decrease in maximum dough consistency during mixing, may be due to a change in the hydrophobic interaction. Monoglycerides are adsorbed to protein hydrophobic regions in the dough, and thus surface hydrophobicity decrease. As a result, these effects of monoglycerides on dough proteins produce a change in the dough's rheological properties. It is considered that monoglycerides mainly bind to gliadin, and thereby relaxes the strong hydrophobic interaction in the gluten matrix. Our results indicate that the rheological properties of the dough and surface hydrophobicity are changed by the addition of monooleate or monoelaidate, while monostearate does not show these effects. Our results from these experiments also suggest that the unsaturations of the carbon chain in a fatty acid are important factors for improvement in the dough properties. The presence of the double-bond component in a fatty acid may cause bonding to the dough protein.

\section{References}

Chung, O.K. and Tsen, C.C. (1975). Distribution of lipids in acid soluble protein components as affected by dough mixing and surfactants. Cereal Chem., 52, 823-832.

Danno, G. and Hoseney, R.C. (1982). Effect of sodium chloride and sodium dodecyl sulfate on mixograph properties. Cereal Chem., 59, 202-204.

Danno, G., Kanazawa, K. and Natake, M. (1978). Improved fractionation of constituent polypeptides from wheat glutenin. Agric. Biol. Chem., 42, 11-16.

Haehnel, W., Jussofie, I., Weitemeyer, C. and Mueller, F. (1994). Investigations on the properties of emulsifiers in yeast leavened dough by means of infrared spectroscopy. I. Experiments on the interaction of emulsifiers with gluten and amino acids. Fat Sci. Technol., 96, 60-64.

Hayakawa, S. and Nakai, S. (1985). Relationships of hydrophobicity and net charge to the solubility of milk and soy proteins. J. Food Sci. 50, 486-491.

Inakuma, T., Aibara, S. and Morita, Y. (1989). The role of glutenin and gliadin in physical dough properties of wheat flours. J. Jpn. Soc. Food Sci. Technol., 36, 437-447.

Inoue, S., Tugita, K., Koike, S., Maruzeni, S. and Kamoi, I. (1995). Effects of fatty acid species of monoglyceride on breadmaking properties. J. Jpn. Soc. Food Sci. Technol, 42, 634-642

Joensson, T. and Toernaes, H. (1987). The effect of selected surfactants on bread crumb softness and its measurement. Cereal Foods World, 32, 482-485.

Khan, K. and Bushuk, W. (1978). Proceeding of the 10th National 
Conference on Wheat Utilization Research, Arizona, November 16 18, pp. 101-115.

Kobrehel, K. and Bushuk, W. (1977). Studies of glutenin X. Effect of fatty acids and their sodium salts on solubility in water. Cereal Chem., 54, 833-839.

Krog, N., Olesen, S.K., Toernaes, H. and Joensson, T. (1989). Retrogradation of the starch fraction in wheat bread. Cereal Foods World, 34, 281-285.

Mendoza-Martinez, A.M. and Sherman, P. (1990a). The interaction of water soluble meat proteins with monoglyceride and diglyceride at the corn oil-water interface and its effect on time-dependent interfacial tension reduction. J. Dispersion Sci. Technol., 11, 331-346.

Mendoza-Martinez, A.M. and Sherman, P. (1990b). The interaction of water soluble meat proteins with monoglyceride and diglyceride at the oil-water interface and its effect on interfacial rheological properties. J. Dispersion Sci. Technol, 11, 347-362.

Mendoza-Martinez, A.M. and Sherman, P. (1991). Protein-glyceride interaction: Influence on emulsion properties. American Chemical Society Symposium Series, pp. 130-137.

Mine, Y., Chiba, K. and Tada, M. (1993). Effect of phospholipid on conformational change and heat stability of ovalbumin. circular dichroism and nuclear magnetic resonance studies. J. Agric. Food Chem., 41, 157-161.
Morad, M.M. and D'Appolonia, B.L. (1980). Effect of surfactants and baking procedure on total water-solubles and soluble starch in bread crumb. Cereal Chem., 57, 141-144.

Riisom, T., Krog, N. and Eriksen, J. (1984). Amylose complexing capacities of cis- and trans-unsaturated monoglycerides in relation to their functionality in bread. J. Cereal Sci., 2, 105-118.

Shiiba, K., Negishi, Y. and Okada, K. (1993). Changes in solubility of wheat glutenin during fermentation. J. Jpn. Soc. Food Sci. Technol, 40, 727-731.

Smith, L.M., Fantozzi, P. and Creveling, R.K. (1983). Study of triglyceride-protein interaction using a microemulsion-filtration method. J. Am. Oil Chem. Soc., 60, 960-967.

Yamauchi, H., Fujimura, M., Ohya, K., Hirakawa, T. and Kobayashi, T. (1992). Role of shortening and monoglyceride on staling of white bread made by the straight dough method. J. Jpn. Soc. Food Sci. Technol, 39, 383-390.

Yuno-Ohta, N., Segawa, Y., Fujii, S., Fujiwara, Y., Kuchiba, M. and Matoba, T. (1988). Intermolecular forces involved in the gelation and gel stability of sesame $13 \mathrm{~S}$ globulin. Agric. Biol. Chem., 52, 1747-1754.

Yuno-Ohta, N., Maeda, H., Okada, M. and Hasegawa, K. (1992). Formation of transparent gels of sesame 13S globulin: Effects of fatty acid salts. J. Food Sci., 57, 86-90. 